\title{
There Ought to be a Law?: Comparative Case Studies in the Role of Community Engagement and Policy Making Targeting HSV-1 Infection Following Ritualized Circumcision
}

\author{
Akiva Turner \\ College of Health Care Sciences, Nova Southeastern University, USA
}

Copyright $(2016$ by authors, all rights reserved. Authors agree that this article remains permanently open access under the terms of the Creative Commons Attribution License 4.0 International License

\begin{abstract}
This paper compares and contrasts two different public health case studies in which public health authorities sought to address HSV-1 infection in Orthodox Jewish communities following ritualized circumcision. Using these cases, the author critiques the use of a governmental regulatory approach when public health authorities target a minority community for a practice which is not valued by the dominant political culture. Lastly, the author describes the benefits of community engagement in addressing such non-emergent public health concerns, particularly if the community involved is a religious minority one.
\end{abstract}

Keywords Public Health Policy, Metzizah B'Peh, Community Engagement, Regulation, HSV-1

\section{Introduction}

Saving Gotham, a book written by Dr. Tom Farley [1] former Health Commissioner of New York City is described as "the behind-the-scenes story of the most controversial public health initiatives of our time" and touts successful policy campaigns against smoking and childhood obesity as well as increasing life expectancy. Throughout reading the book, I was struck by the top down policy approach. More importantly, the whole pursuit of policy seemed to ignore community engagement, or even concerns for the need for community engagement, outside of meetings with industry special interest groups.

I am not the first to note this absence in the policy strategies of the New York City Department of Health and Mental Hygiene (NYC DOHMH). Two recent articles have discussed New York City's public health successes during the last administration in areas such as trans-fat restrictions, calorie labeling, and smoking. [2, 3] Both articles focus on how successful the NYC DOHMH was at mobilizing the governmental workforce and power structures and/or at harnessing the city's powerful Mayor's support, but not on how successful the NYC DOHMH was at engaging communities. In one article, the author [3] praises the NYC DOHMH policy successes but identifies the core characteristics of these successes during Dr. Farley's tenure, as well as that of his predecessor Dr. Thomas Friedman, to be paternalism, taxation, regulation and a paucity of community input.

Using a specific case study involving ritualized circumcision in some New York City Orthodox Jewish communities, I will briefly describe the power of the NYC $\mathrm{DOHMH}$ to dictate policy. I will then contrast the $\mathrm{NYC}$ DOHMH's handling of the religious practice with that of the public health authorities in nearby Rockland County. I will then move into a discussion of the value of community engagement in the policy making process. My purpose here is not to review Dr. Farley's book as readers can make judgments of that work on their own. I only include it here for context. Instead my purpose is to analyze religious practice cases to pursue a question. As public health increases its policy approaches to improve and protect the public's health, should policy making be wed with community engagement?

\section{The NYC DOHMH and Power}

The NYC DOHMH is independent of the New York State Department of Health and has its own Board of Health. Most members of the Board of Health are appointed by the Mayor with the "consent" of the elected city council. Some, but not all, of the board members are physicians and the New York City Health Commissioner, who oversees the NYC DOHMH, 
serves as its Chair. According to the NYC DOHMH [4]:

The 11-member Board of Health remains a vital force today. Most members - appointed by the Mayor with the consent of the City Council - serve six-year terms. Each Board member is a recognized expert, and the group represents a broad range of health and medical disciplines. They serve without pay and, like judges, cannot be dismissed without cause. As the overseer of New York City's Health Code, the Board has enacted countless measures to improve the wellbeing of New Yorkers over the years - including a ban on interior lead paint, modern tuberculosis control provisions and, more recently, a plan for eliminating trans-fat from restaurants.

The Board of Health has the authority to change, create, and pass the New York City Health Code as long as the code does not conflict with state/federal law, minimize any restrictions in state/federal law, add to an area of law intended to be occupied solely by state/federal law, or unlawfully violate civil rights. The creation of, and changes to, the code are written by the NYC DOHMH staff and proposed to the Board. At a public hearing, the Board discusses and votes on the code. Passing the health code is a tremendous regulatory power for a body not directly elected by its citizens.

Throughout Dr. Farley's book [1], this power seems to have been combined with a mixture of urgency, frustration, ambition, and a noble crusading mission to make people live healthier immediately and to save them from themselves. All public health issues, including chronic ones, were as urgent as a disease outbreak. This mind-set lead to some successful policy changes as noted above, but in some cases may have left some communities disenfranchised and unengaged at best, and inappropriately targeted and resistant at worst.

Additionally, there appears to be a human tendency to want to ban or legislate against that which is not important to oneself or to one's own community. Instead, one tends to look for more creative ways to approach problems and health risks that are consistent with one's own community's values and practices, while seeking to ban or inhibit those of others. As the following case will demonstrate, the use of legal authority can become inappropriate when targeting activities valued by minority communities and not by members of the dominant cultures.

\section{Metzizah B'Peh and the NYC DOHMH: Regulation}

During Dr. Farley's tenure at the NYC DOHMH, he, the department's disease control staff, and Mayor Michael Bloomberg became concerned over investigations of herpes simplex virus (HSV) infections among a small number (11 HSV-1 positives) of male infants occurring over eleven years in some Orthodox Jewish communities. [5] The infections occurred following a ritualized circumcision conducted on the eighth day of the baby boy's life as religiously required. As part of the circumcision, the circumciser (mohel) performed the centuries old practice of metzizah b'peh (MPB) in which the mohel briefly places his mouth with a small amount of wine on the wound. Some believe MBP to be a biblically obligated way to perform the circumcision, and that a circumcision without MBP would be invalid. The department, based upon its investigation into some of the above cases of HSV-I infection in Orthodox Jewish male infants, concluded that the infants' infections were related to MBP. [5] The quality of these investigations and veracity of these conclusions have been questioned and debated elsewhere. $[6,7]$

In response to these investigations, Dr. Farley and Mayor Bloomberg publicly declared in the media that MPB should not be performed at all and that they would do all they could to stop the practice. They were backed unquestioningly by prestigious professional groups, including the American Academy of Pediatrics. [8]

The department first distributed educational materials about the "dangers" of MBP to Orthodox Jewish communities. Then, in September 2012, the NYC DOHMH's Board of Health voted to mandate that any religious practitioner who circumcises with MBP must require a signed "consent" form from the parents before proceeding with the circumcision. [9] The complete banning of the religious practice would have been a risky constitutional legal venture, and the consent seemed a reasonable analogy to ethical medical practices.

The consent, however, was not really a true consent explaining risks and benefits, but instead was a warning from the NYC DOHMH to the parents that MPB should not be done at all. It did not put forth information about the known risks and benefits of MBP but instead required the mohel, a non-licensed unregulated practitioner, to speak for the NYC $\mathrm{DOHMH}$ and perhaps violate his religious obligations. The religious practitioners, backed by their communities, refused to require the "consent" forms, took the city to court, and there it was litigated for some time but was not completely resolved before a political change occurred. [8,9]

I have previously published about this case and criticized the science and the ethics of the NYC DOHMH's policy approach. [8] After a change in political administrations, and Dr. Farley's departure, the NYC DOHMH changed its policy after, but not because of, my critique. Although Dr. Farley did not include this case in his book, in an interview following its publication, he lamented that the NYC DOHMH had not continued the MBP policy he had championed and criticized the change in direction. [10]

This change in direction came after Mayor Bloomberg's term ended and after Dr. Farley's resignation. The NYC $\mathrm{DOHMH}$ repealed the warning requirement and began to work more closely with the community. This presumably because of political pressure from the new mayor, Bill DeBlasio, and because of reports coming out of nearby Rockland County, New York. In some HSV-1 cases in Jewish males factually similar to those in New York City, the 
public health authorities in Rockland County had ruled out the mohel as the source of infection. [11]

\section{Metzizah B'Peh and Rockland County: Engagement}

Prior to the New York City Health Code's MPB provision repeal, Rockland County had already engaged its Orthodox Jewish community and had come to a very different solution to the same problem. Rockland County is home to a large Orthodox Jewish community that also practices MBP. Unlike the NYC DOHMH, public health authorities in Rockland County do not have the ability to create their own law or code and instead undertook a respectful strategy to engage the Orthodox community. The community and the public health authority worked together to develop a solution without condemning the religious practice itself. [11, 12]

The community and the public health authority developed a policy/protocol. In this policy/protocol, a baby's parents are not required to sign a document that would essentially declare that the parents would be defying official public health directives and putting their child in danger. Further, mohelim are not required to deliver such a warning. Instead, under the agreed upon policy/protocol, a male baby with HSV symptoms, and who has had a circumcision with MPB, is tested for HSV-1 infection. The state lab then makes a determination if the baby has HSV-1 infection. As part of the search for the potential source of infection, the public health authorities swab and test all potential source contacts, including the mohel, to determine if there is a HSV-1 strain match with the infant. The public health authorities conduct sixty swabs over a period of thirty to sixty days. While the testing is ongoing, the mohel does not perform MBP. [11, 12]

The mohelim and the community have been cooperating in the protocol's implementation. Mohelim who may not live in Rockland County have even travelled at their own expense to assist the Rockland County public health authorities. The community's rabbinical authorities have agreed that if a mohel is found to be the cause of infection he will stop, and will be banned from performing MBP in any locality for the rest of his life. [11, 12] An outsider may not understand how this could be enforceable, but these are tightly connected communities in which community influence, rabbinical pressure, and the mohel's own religious beliefs, can serve as a powerful enforcement. In addition, the public health authorities are working with the mohelim to develop procedures that can reduce the risk of transmission in the first place. [11]

Following implementation of this policy/protocol, out of three possible cases of HSV infection with MPB that occurred in the county, the mohel was ruled out as the source in two of the cases and one case was inconclusive. [11] Both cases in which the mohel was ruled out would have been considered to be cases caused by MPB if they had occurred under the jurisdiction of the NYC DOHMH and thus counted as part of the small number of cases used to declare MBP inherently dangerous.

Dr. Oscar Alleyne, Rockland County's Director of Epidemiology, considers the cooperation that he and his department have with the community to be a major breakthrough. As Dr. Alleyne put it, "(w)e are a health department. We can't legislate the procedure. We don't have the ability to do so and there is the question of how efficacious it would be anyway. But there are ways for us to encourage practices to be safer." Though the Rockland County policy/protocol has not yet been formally evaluated, the goal for Dr. Alleyne is to develop a comprehensive approach that establishes community collaboration with scientific and epidemiological evidence in order to reduce harm. [11]

Following Rockland County's lead, New York City reconsidered its top down regulatory approach. In a New York Times op-ed Dr. Mary Bassett [13], Dr. Farley's successor as Health Commissioner, defended a change in policy stating, "( $\mathrm{t})$ he requirement that moehlim obtain parental consent forms generated a tremendous opposition and made implementation not practically possible. Simply put, the current approach is not feasible, and we must try something different. Such cooperation will make identification of mohelim who may have transmitted the infection more likely. Further, the community will urge mohelim to get tested and support the department when it determines that a mohel be barred from practicing."

In other words, in the MBP case, the less proscriptive approach may be a more enduring and more effective practice. In New York City and Rockland County respectively, the community either fought the health department or cooperated depending upon the public health authority's strategy. These cases underscore the potential consequences of not, and the benefits of, including the community in policy development.

\section{Community Engagement and Policy}

Community engagement and participation is a core function of public health and has been identified as such by both the World Health Organization (WHO) and the Centers for Disease Control (CDC). [14] Community engagement "involves dynamic relationships and dialogue between community members and local health department staff, with varying degrees of community and health department involvement, decision-making, and control." [14] Community may include "individuals, groups, organizations, and associations or informal networks that share common characteristics and interests based upon place, issue, or identity based factors." [14] Some scholars have attempted to describe community engagement by way of categorization or increasing levels of engagement. According to Bowen [15] there are three levels of community engagement which exist on a continuum. First there is transactional community engagement. In transactional community engagement, the community is passive, and more a receiver of information. 
Second, there is two-way communication. At this level, the community is considered a stake-holder, but not an equal to the public health authority, and may attend meetings convened by the public health authority. In the last level, shared decision making, the community is a partner, rising even to the level of being a co-owner.

Morgan and Lifshay [14] provide a more detailed model. Their model is more applicable to public health as it was developed using a decade of public health cases within the context of population level approaches. They describe a "ladder" of community participation and acknowledge that the level of engagement may depend somewhat upon the issue and circumstances at hand. These ladder rungs from the lowest to the highest levels of engagement are: 1) department initiates and takes directive action most commonly during emergencies; 2) department informs and educates; 3) department solicits periodic/ limited community input through vehicles such as surveys and focus groups about services; 4) department seeks comprehensive community consultation through ongoing in depth input by way of coalitions and advisory boards; 5) community members are conduits or bridges of information to and from the department such as using lay educators; 6) community and the department share power and together define and solve the problem; and 7) community initiates and directs action.

Applying this ladder to the cases at hand, the NYC DOHMH appears to have jumped from the first rung, which does have its place in the case of emergencies and other urgent circumstances, to joining Rockland County at the sixth rung, one in which the community and the department developed a shared policy/protocol. Given the small number of potential HSV-1 cases with MBP, the fact that any public health response would impact a small minority community, and that the community activity involves a centuries old safely practiced religious ritual, this ladder rung is much more appropriate and perhaps more proportionate, fair, and just. This level of engagement can avoid the discriminatory targeting of a minority group's practices not valued by the dominant culture of which public health authorities and systems are a part. Although reducing HSV-1 infection is of course an important goal, this public health goal is now contextualized with potential benefits of community engagement in order to be effective and produce lasting results.

\subsection{Benefits of Community Engagement}

Though not connected to levels of community of engagement, various benefits of community engagement have been generally described in the literature. These benefits range from physical, to psychological, to social. Sarrami-Faroushani et al. [16] claim that community engagement increases community awareness and involvement in health-related decisions. While Palmer-Wackerly et al. [17] bring a more individual benefit suggesting that actively involving persons in interventions leads to greater attention to messages, consideration of the messages, and a greater likelihood of taking action.

Lai and Hynie [18] propose that community engagement creates a psychological sense of community that is associated with a range of positive psychological outcomes including feelings of autonomy, environmental mastery, purpose in life, personal growth and self-acceptance. It also contributes to the community's social capital (i.e. relationships/structures that promote cooperation for mutual benefit), thus allowing the community to progress from individual to collective action in order to better influence and change the well-being of community members.

Needless to say these benefits may not be immediate ones. According to Bowen [14] community engagement provides long-term benefits but not necessarily immediate benefits, something that could be frustrating to those passionate to produce immediate results. On the other hand, creating these benefits represents a more holistic and contextual approach to health, one that should be part of the mission of public health. However, this mission may require that the governmental public health authority exercise restraint in its use of power.

\subsection{Power and Community}

Knowledge can be a source of power, and healthcare professions, as well as public health, have a monopoly of knowledge. This monopoly can be very undemocratic when used inappropriately. [19] When this monopoly of knowledge is combined with the governmental power to dictate through laws and regulations, the consequences in some cases may be fruitful but in other cases may also be detrimental to community empowerment and decision-making or lead to community resistance.

In the MPB case, the NYC DOHMH justified taking regulatory and legal actions with claims that doing so was necessary to save a very small number of babies from illness and death. However, the question was asked inside and outside of court, why this heavy handed approach was so necessary given such small numbers of possible infections compared to all the other causes of infant morbidity and mortality in the city of New York including HSV infection acquired from other sources and occurring outside the Orthodox Jewish community. [7, 8]

The community felt persecuted, discriminated against, and stigmatized but given the Orthodox Jewish community's cohesiveness and leadership of knowledgeable rabbis and experts, instead of being disempowered, the community responded with resistance. Meanwhile, if Dr. Farley's accounts [1] of the department's dynamics are accurate, the NYC DOHMH staff was probably at a minimum frustrated since the community would not give in to, or agree with, its expert opinions or its desire to enforce those opinions. In short, the exercise of power did not work and instead led to legal conflict and mistrust.

On the other hand, the NYC DOHMH's new approach, following Rockland County's lead, may create a longer lasting community relationship that can be beneficial in 
dealing with a multitude of health issues within the community. That is, however, if there is a true and sincere long term commitment to engagement. According to Barnett [20] "(i)n reality, bringing all stakeholders to the table for a meaningful dialogue on how best to support a healthier community requires long-term commitment on every one's part."

In the end, however, regulatory and legal strategies may be appropriate if not abused and if affected communities are engaged to the fullest extent possible with genuine respect instead of with derision. As argued by Simoes and Sumaya [21] "(a)lthough health policy development may seem to be dominated by high levels of government, powerful policy organizations... and special interest groups, the community and its citizens should be actively involved and consulted on policy goals and directions." Health gains from engaging communities require that communities also have power so they can make meaningful decisions. This approach to public policy making will embody aspirations far greater than just improving physical health but also aspirations for maintaining a fair and healthy society. [22] Public health as a governmental activity should, indeed has a responsibility, to pursue both aspirations.

\section{Conclusions}

Though mandates and proscriptive measures can be effective in some cases, when community engagement is possible, such measures should not be relied upon exclusively in dealing with public health issues, absent a true emergency, particularly if the behavior or activity of concern affects a minority group. Public health authorities, as part of a dominant culture, may attach greater social value to their own practices and be more willing to accept risks associated with those practices, while devaluing the practices of minority groups in relation to risk. A disproportionate use of government power to target minority behaviors and practices could bypass or miss opportunities for long term community engagement to solve a multitude of health issues.

Public health is tasked with assessing, investigating and preventing diseases as well as promoting health, but it is also tasked with engaging and empowering communities, one of its core functions. To disregard communities in order to mandate change, while looking at a particular health issue in a vacuum, may be ineffective in some cases and in the end may also lead to community resistance and a lack of trust. The community's ability to resist these mandates may vary based upon the community's cohesiveness, leadership and resources. Nevertheless, even in cases where resistance may be less likely, the top down policy approach may lead to unjust discrimination and jeopardize the core public health function of engaging and empowering communities.

\section{REFERENCES}

[1] T. Farley. Saving Gotham, W. W. Norton \& Co., New York, 2015.

[2] K.R. Issett. M.J. Laugesn. D.H. Cloud. Learning from New York City: a case study of public health policy practice in the Bloomberg administration, Journal of Public Health Management Practice, Vol.21, No.4, 313-322, 2015.

[3] P.J. Imperato. Public health initiatives in New York City during the Bloomberg administration, Journal of Public Health Management Practice, Vol .21, No.4, 3213-324, 2015.

[4] New York City Department of Health and Mental Hygiene, Board of Health, Online available from http://www1.nyc.gov /site/doh/about/about-doh/board-of-health.page.

[5] Centers for Disease Control, Neonatal herpes simplex virus infection following Jewish ritual circumcision that included direct oralsuction, MMWR, Vol.61, No.22, 405-409, June 8, 2012, Online available from: http://www.cdc.gov/mmwr/pre view/mmwrhtml/mm6122a2.htm.

[6] B. Leas. C.A. Umscheid. Neonatal herpes simplex virus type I infection and Jewish ritual circumcision with oral suction: a systematic review, Journal of the Pediatric Infectious Disease Society, July 23, 2014, doi:10.1093/jpids/piu082.

[7] D. Berman. B. Breuer. A. Federgruen. No conclusive evidence on circumcision rite and herpes, The Jewish Daily Forward, March 9, 2014 Online available from http://www.f orward.com/articles/194118/no-conclusive-evidence-on-circ umcision-rite-and-he/\#ixzz2xkoyn843.

[8] A. Turner. Metzizah be'peh: public health ethics and an attempt to regulate religious circumcision, Internet Journal of Law Healthcare and Ethics, Vol. 10, No.1, 2014 doi:10.5580/IJLHE.14854.

[9] New York City Department of Health and Mental Hygiene, Notice of Adoption, Online available from http://www.nyc.gov/html/doh/downloads/pdf/notice/2012/no tice-adoption-amend-article181.pdf.

[10] D. Goldberg. Bloomberg health commissioner: city wrong to repeal circumcision forms, Capital New York, October 12, 2015, Online available

fromhttp://www.capitalnewyork.com/article/city-hall/2015/1 0/8579265/bloomberg-health-commissioner-city-wrong-repe al-circumcision-forms.

[11] D. Goldberg. Rockland takes a new tack on risky circumcisions, Capital New York, January 9, 2015, Online available from http://www.capitalnewyork.com/article/city-h all/2015/01/8559644/rockland-takes-new-takc-risky-circumc isions.

[12] M.G. West. M.H. Saul. City alters course on circumcision ritual, The Wall Street Journal, February 25, 2015, Online available from http://wsj.com/articles/city-alters-course-on-c ircumcion-ritual-1424915497.

[13] M. Bassett. Letter to the Editor, New York Times, March 11, 2015, Online available fromhttp://www.nytimes.com/2015/0 3/11/opinion/orthodox-jews-and-new-yorks-circumcision-rul e.html.

[14] M.A. Morgan. J.Lifshay. Community engagement in public health, Online available fromhttp://cchealth.org/public-healt h/pdf/community_engagement_in_ph.pdf. 
[15] F. Bowen. A. Newenham-Kahindi. I. Herremans. When suits meet roots: the antecedents and consequences of community engagement strategy, Journal of Business Ethics, Vol. 95, No. 2, 297-318, 2010.

[16] P. Sarrami-Foroushani. J. Travaglia. D. Debono. J. Braithwaite. Implementing strategies in consumer and community engagement in health care: results of a large-scale scoping meta-review, BMC Health Services Research, Vol. 13, 2014 Online available from http://biomedcentral.com/14 72-6963/14/402.

[17] A.L. Palmer-Wackerly. J.L. Krok. P.M. Dailey. L. Kight. J.L. Kreiger. Community engagement as a process and an outcome of developing culturally grounded health communication interventions: an example from the DECIDE project, Vol. 53, 261-274, 2014.

[18] Y. Lai. M. Hynie. Community engagement and well-being of immigrants: the role of knowledge, Online available from http://www.metropolis.net/pdfs/immi_health/Immigrant\%20 Mental\%20Health\%20-\%20pgs93-97.pdf.

[19] G. Scrambler. Health and Social Change: A Critical Theory, Open University, Buckingham, 2002.

[20] K. Barnett. Toward a more strategic approach to community engagement - a commentary, Journal of Health and Human Services Administration, Vol. 25, 204-213, 2002.

[21] E.J. Simoes. C.V. Sumaya. Protecting and enhancing health: community engagement, collaborations, and incentives for prevention, Journal of Primary Prevention, Vol. 31, 21-29, 2010 .

[22] L. Kenyon. F. Gordon. Community engagement from a professional to a public perspective, Community Practitioner, Vol. 82, No. 2, 22-25, 2009. 